\title{
The first report on entomopathogenic effect of Fusarium avenaceum (Fries) Saccardo (Hypocreales, Ascomycota) against rice weevil (Sitophilus oryzae L.: Curculionidae, Coleoptera)
}

\author{
Y.A. Batta \\ Department of Plant Production and Protection, Faculty of Agriculture, An-Najah National \\ University, Nablus, West Bank, Palestinian Authority
}

\begin{abstract}
This study aimed to evaluate the entomopathogenic activity of Fusarium avenaceum (strain 10A) against adults of Sitophilus oryzae infesting wheat grain. Bioassays were carried out to determine the adult mortality of $S$. oryzae when the conidial suspension of the fungus strain was applied using three types of fungus treatment. Results obtained have indicated significant differences $(\mathrm{P}=0.05)$ in the mean percentage of adult mortality due to the treatment with the fungus compared to the control. The highest mean percentage of adult mortality was obtained by the direct spraying of $S$. oryzae adults with the fungus conidial suspension before introduction of the treated adults into pots containing wheat grain; the lowest mean percentage of adult mortality was obtained by spraying the inner surfaces of pots with the fungus conidial suspension before introducing the grain and insects. This study demonstrated the typical growth of $F$. avenaceum on the outer surfaces of the dead treated adults of $S$. oryzae. Presence of the external fungus growth on the dead insects indicated that the death of $S$. oryzae adults was attributed to the fungus infection. Results obtained in the present paper represent the first record of efficacy of $F$. avenaceum against a coleopteran stored-grain insect, mainly including $S$. oryzae.
\end{abstract}

Correspondence: Yacoub A. Batta, Department of Plant Production and Protection, Faculty of Agriculture, An-Najah National University, Nablus, West Bank, Palestinian Authority.

E-mail: yabatta@najah.edu -yabatta@windowslive.com

Key words: Fusarium avenaceum, Sitophilus oryzae, entomopathgenic effect, bioassays, direct application.

Received for publication: 26 April 2012.

Revision received: 8 September 2012.

Accepted for publication: 12 September 2012.

CC Copyright Y.A. Batta, 2012

Licensee PAGEPress, Italy

Journal of Entomological and Acarological Research 2012; $44: e 11$

doi:10.4081/jear.2012.e11

This article is distributed under the terms of the Creative Commons Attribution Noncommercial License (by-nc 3.0) which permits any noncommercial use, distribution, and reproduction in any medium, provided the original author(s) and source are credited.

\section{Introduction}

Rice weevil (Sitophilus oryzae) is one of the most serious threats to stored grain. Adults and larvae of this insect attack healthy grain, especially cereals, causing extensive damage, especially to those cereals stored under high temperatures and medium relative humidity $(\mathrm{RH})$ $\left(>25^{\circ} \mathrm{C}\right.$ and $80 \%$ ) (Padin et al., 2002). During feeding, these insects consume all of the internal contents of the attacked grain leaving them as empty shells (Dal Bello et al., 2000).

Many types of control measures can be undertaken against $S$. oryzae. Chemical and biological control measures are the most common (Dal Bello et al., 2000; Lee et al., 2001; Fang et al., 2002; Pungitore et al., 2005; Batta, 2008; Govindan \& Nelson, 2009; Yankanchi \& Gadache, 2010). Biocontrol of $S$. oryzae using entomopathogenic fungi is still uncommon and very few species of these fungi (e.g., Metarhizium anisopliae and Beauveria bassiana) have been used to control S. oryzae (Padin et al., 2002; Batta, 2004).

Fusarium species are generally considered soil borne fungi because of their abundance in the soil and their frequent association with plant roots as parasites or saprophytes. These species have usually been reported as plant pathogens causing serious diseases on many plant species (e.g., vascular wilts on a wide range of horticultural crops, crown rot and root rot diseases on many crops, head blight on cereal grain and other plant species) (Booth, 1971). However, some of these species may act as weak to virulent entomopathogens and may live as saprophyte on dead insects (Teetor-Barsch \& Roberts, 1983). As entomopathogens, some Fusarium species have been reported to cause moderate to high levels of infection, principally against homopterous and dipterous insects. However, low to moderate levels of infections with these entomopathogens have been reported from insects of other orders (e.g., Coleoptera and Lepidoptera) (Teetor-Barsch \& Roberts, 1983). Many species of entomopathogenic Fusarium may kill their host insects through the activity of toxins produced by penetrating hyphae (Gupta et al., 1991).

Fusarium avenaceum was one of the entomopathogenic species of Fusarium that has been isolated from a number of insect species, and its pathogenicity to insects has been demonstrated in few species, such as greenhouse whitefly, Trialeurodes vaporariorum (EleonoraRojas et al., 2003), spruce budworm, Choristoneura fumiferana, (Strunz \& Strongman, 1988) and wheat stem sawfly, Cephus cinctus, (Sun, 2008). To the best of our knowledge, no reports are yet available on the entomopathogenic activity of $F$. avenaceum against $S$. oryzae or any other coleopteran insects of stored grain. Therefore, the objectives of the present research were: i) to assess the efficacy of $F$. avenaceum (strain 10A) against $S$. oryzae adults by applying the fungus conidial suspension in different ways, then comparing the treatment effect by 
calculating the adult mortality percentage in the different types of treatments; and ii) to demonstrate that infection with $F$. avenaceum (strain 10A) can kill the adults of $S$. oryzae by first colonizing the internal organs of treated insects and then by the growth of the internal hyphae of the fungus on the outer surfaces of dead insects.

\section{Materials and methods}

\section{Insect rearing}

A local strain of Sitophilus oryzae (S025) was used in the present bioassays. Adults of this strain were reared on wheat grain (variety: Anbar) stored in plastic pots (90 mm diameter and $140 \mathrm{~mm}$ deep). During rearing, each pot was covered with a piece of cheesecloth fastened with a rubber band on the top. The rearing pots containing the grain and insects were kept in an incubator with fixed conditions $\left(20 \pm 1^{\circ} \mathrm{C}, 80 \pm 5 \% \mathrm{RH}, 14 / 10 \mathrm{~h}\right.$ light/dark (L/D) photoperiod). To exclude any possibility of insect mortality during bioassays due to aging, young adults of $\mathrm{Fl}$ generation were collected from rearing pots and then used for conducting bioassays.

\section{Fungus strain}

Strain (10A) of Fusarium avenaceum was used in the present study. It was originally isolated by our laboratory from infected nymphs of citrus whitefly (Dialeurodes citri Ashmead, Aleyrodidae, Homoptera) on Sabouraud dextrose agar (SDA) culture medium amended with chloramphenicol ( $250 \mathrm{mg} / \mathrm{L}, \mathrm{w} / \mathrm{v})$ then sub-cultured on SDA medium for ten days before being stored at $4^{\circ} \mathrm{C}$ as a pure culture of the fungus. To conduct bioassays, the fungus obtained from the pure culture was sub-cultured on SDA medium. Morphological and molecular characteristics of the fungus species, such as Fusarium avenaceum, were confirmed both by our laboratory and by the molecular biology laboratory at An-Najah National University. These characteristics conform to those described by other investigators for the genus and species of the fungus (Nelson et al., 1994; Satyaprasad et al., 2000; Waalwijk et al., 2004; Leslie \& Summerell, 2006). A pure culture of the fungus strain grown for 15 days on the same medium was used to conduct bioassays. The fungus culture was characterized by an abundant cottony mycelial growth that varies from white to light yellow in color with pale orange sporodochia

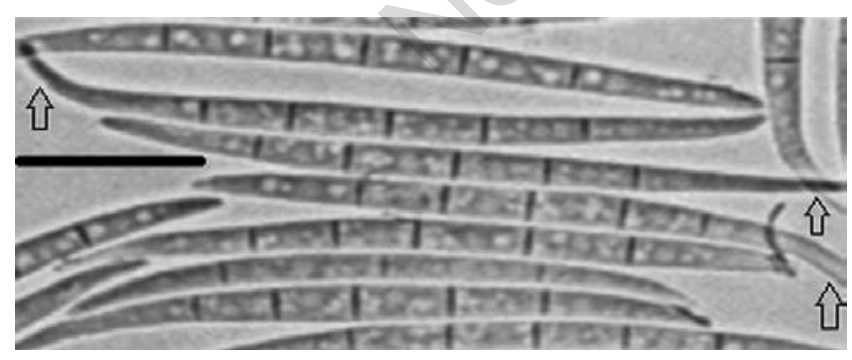

Figure 1. Typical macroconidia of Fusarium avenaceum (strain 10A) formed in sporodochia observed in the fungus culture on Sabouraud dextrose agar medium or borne by the mycelium of the fungus strain appeared on the external surfaces of dead Sitophilus oryzae adults due to infection with the fungus as shown in Figure 2. Each mature macroconidium consists of 6 cells (multicellular with 5 internal septa) and its apical cell is long and tapering to a point; it may be bent (arrows). Average dimensions are $57.7 \mu \mathrm{m}$ long and $4.8 \mu \mathrm{m}$ wide ( $\mathrm{n}=100$ macroconidia; scale bar $20 \mu \mathrm{m}$; magnification: 950x). containing macroconidia, the typical conidia of the fungus species. These macroconidia are long and slender, straight to slightly curved in shape. The mature conidia are multicellular with 6 cells and usually have 5 internal septa (Figure 1). The basal cell of these conidia may have a slight notch but the apical cell is long and tapering to a point; it may be bent (arrows in Figure 1).

Neither microconidia (fusoid in shape with 1 or 2 septa) nor chlamydospores (single or clustered or chain) were observed in the fungus culture. Therefore, the conidial suspension of the fungus that has been prepared from this culture and used for bioassays has contained only the typical macroconidia of the fungus strain.

\section{Inoculation method}

A conidial suspension of $F$. avenaceum was prepared from a 15-day old pure culture of the fungus strain on SDA medium. The concentration of conidia in the suspension was $4.0 \times 10^{4}$ conidia $/ \mathrm{mL}$ and the total volume of conidial suspension that has been used for inoculation was $2.0 \mathrm{~mL}$ per replicate. The technique of inoculation used during bioassays consisted of spraying the conidial suspension of the fungus onto: i) adult insects of $S$. oryzae before their introduction into grains placed in plastic pots; or ii) inner surfaces of plastic pots (treated before introduction of insects and wheat grains); or iii) grains already placed in plastic pots (treated before introduction of insects). The details of the technique will be described below.

\section{Bioassays}

Plastic pots (90 mm diameter, $140 \mathrm{~mm}$ deep) were used to carry out bioassays. Each pot was covered with a piece of cheesecloth fastened with a rubber band after introduction of $10 \mathrm{~g}$ of wheat grain (variety: Anbar) and 20 insects of $S$. oryzae adults (young F1 adults). Four types of treatments were used during bioassays: i) Treatment 1 represents spraying of the inner surfaces of each plastic pot with the conidial suspension before introduction of wheat grain and adult insects; ii) Treatment 2 represents direct spraying of the adult insects with the conidial suspension before their introduction into each pot with wheat grain already introduced; iii) Treatment 3 represents direct spraying of the grain with the conidial suspension after their introduction into each pot. The insects were introduced into grain after the treatment; and iv) the control which represents pots containing non-treated insects and non-treated grain with conidial suspension. Spraying of the conidial suspension during bioassays was performed using a small-calibrated hand sprayer (1 L capacity). The sprayer was standardized to apply fine jetting sprays with $0.5 \mathrm{~mL}$ spray volume for each jetting spray. A total volume of $2.0 \mathrm{~mL}$ (4 jetting sprays) of the conidial suspension was applied per replicate and four replicates were used per treatment. The treatments were distributed in a completely randomized design and the experiment was repeated 3 times under the same conditions to confirm the results. An incubator with fixed conditions $\left(20 \pm 1^{\circ} \mathrm{C}, 80 \pm 5 \% \mathrm{RH}\right.$ and $14 / 10 \mathrm{~h}, \mathrm{~L} / \mathrm{D}$ photoperiod) was used during bioassays. Results were the average of the 3 repeated experiments conducted under the same conditions. To ensure that the infection with the fungus was the cause of death of treated adult insects, the dead insects were incubated under humid conditions at $20 \pm 1^{\circ} \mathrm{C}$ for three days using tightly closed Petri dishes with moistened filter papers. Before introduction into dishes, the dead insects were surface sterilized using $2 \%$ sodium hypochlorite solution for 3 min then rinsed three times with sterile distilled water then placed on clean glass slides to avoid the dead insects getting too wet if placed directly in the bottom of dishes.

\section{Assessment}

After ten days of applying the conidial suspension of the fungus in each type of the treatments, the dead adults of $S$. oryzae in each replicate were counted. The mean percentage of adult mortality was then calculated in each treatment type. This calculated mortality is called 
observed mortality. Corrected mortality using Abbott's formula for control mortality was calculated from observed mortality then used to assess the entomopathogenic effect of the fungus. The mycosis that appeared on the outer surfaces of the dead insects after incubation under humid conditions was microscopically examined to verify whether the fungus growth and the conidia produced on the outer surfaces conformed to those that characterize our fungus strain.

\section{Statistical analysis}

The data obtained from bioassays on the mean percentage of corrected $S$. oryzae adult mortality were angularly transformed and then analyzed statistically using analysis of variance (ANOVA). Abbott's formula for calculating the corrected mortality from observed mortality was used [Abbott's formula=(Mortality observed-Mortality control/100-Mortality control $) \times 100$ ]. The significant differences between the treatment means at $\mathrm{P}=0.05$ were determined by F-test and the treatment means were separated using Tukey's HSD test. SAS software version 8 (2000) was used for statistical analysis (Institute Inc., Cary, NC, USA).

\section{Results}

Comparison of the treatment effect with $F$. avenaceum against $S$. oryzae adults has indicated that significant differences $(\mathrm{P}=0.05)$ were obtained in the mean percentage of corrected adult mortality in the different types of treatments used in bioassays (Table 1). Therefore, the highest mean percentage of corrected adult mortality (94.86\%) was obtained with Treatment 2 by direct spraying of insects with conidial suspension before their introduction into pots containing wheat grain followed by the mean percentage of corrected adult mortality (68.88\%) obtained in Treatment 3 by direct spraying of the grain already introduced into pots before introduction of insects, and then by the mean percentage of corrected adult mortality (52.22\%) obtained in Treatment 1 by spraying inner surfaces of pots before introduction of the grain and insects. However, the lowest mean percentage of adult mortality (5\%) was obtained in the control (Table 1). Therefore, the most effective treatment was the direct spraying of the adult insects with the conidial suspension of the fungus; this gave the highest mortality percentage in the treated adults.

Incubation of dead insects of $S$. oryzae obtained from bioassays, under humid conditions at $20 \pm 1^{\circ} \mathrm{C}$ for three days resulted in the appearance of white to light-yellow cottony mycelium growth, typical of F. avenaceum on the outer surfaces (Figure 2).

Microscopic examination of this mycelium has indicated the presence of aerial multicellular conidia typical of $F$. avenaceum macrocodidia. These macroconidia were long and slender, straight to slightly curved in shape (Figure 1). At maturity, they consist of 6 cells with 5 internal septa and the apical cell of these conidia is long and tapering to a point; it may be bent (arrows in Figure 1). These conidia ( $\mathrm{n}=100$ conidia) were on average $57.7 \mu \mathrm{m}$ long $(48-63 \mu \mathrm{m})$ and $4.8 \mu \mathrm{m}$ wide $(4-6 \mu \mathrm{m})$.

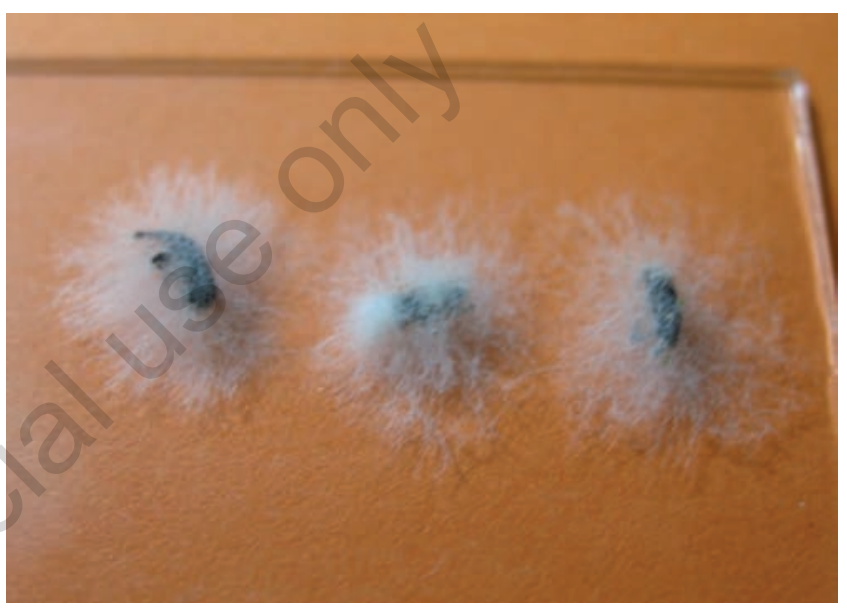

Figure 2. Typical mycosis observed on the external surfaces of dead Sitophilus oryzae adults due to infection with Fusarium avenaceum (strain 10A). A white cottony mycelium growth characteristic of $F$. avenaceum appeared on the external surfaces of dead adults after three days of incubation under humid conditions at $20 \pm 1^{\circ} \mathrm{C}$. Typical macroconidia formed by the fungus on the dead insects were microscopically observed and examined.

Table 1. Percentage of mortality (\%) of Sitophilus oryzae adults ten days after treatment with conidial suspension of Fusareum avenaceum (strain 10A). Incubation was carried out at $20 \pm 1^{\circ} \mathrm{C}, 80 \pm 5 \% \mathrm{RH}$ and $14 / 10 \mathrm{~h}, \mathrm{~L} / \mathrm{D}$ photoperiod. Four replicates per treatment were used and 20 adults per replicate were introduced into each plastic pot with wheat grain. The experiment was repeated 3 times and average data were presented and then corrected according to Abbott's formula for corrected mortality.

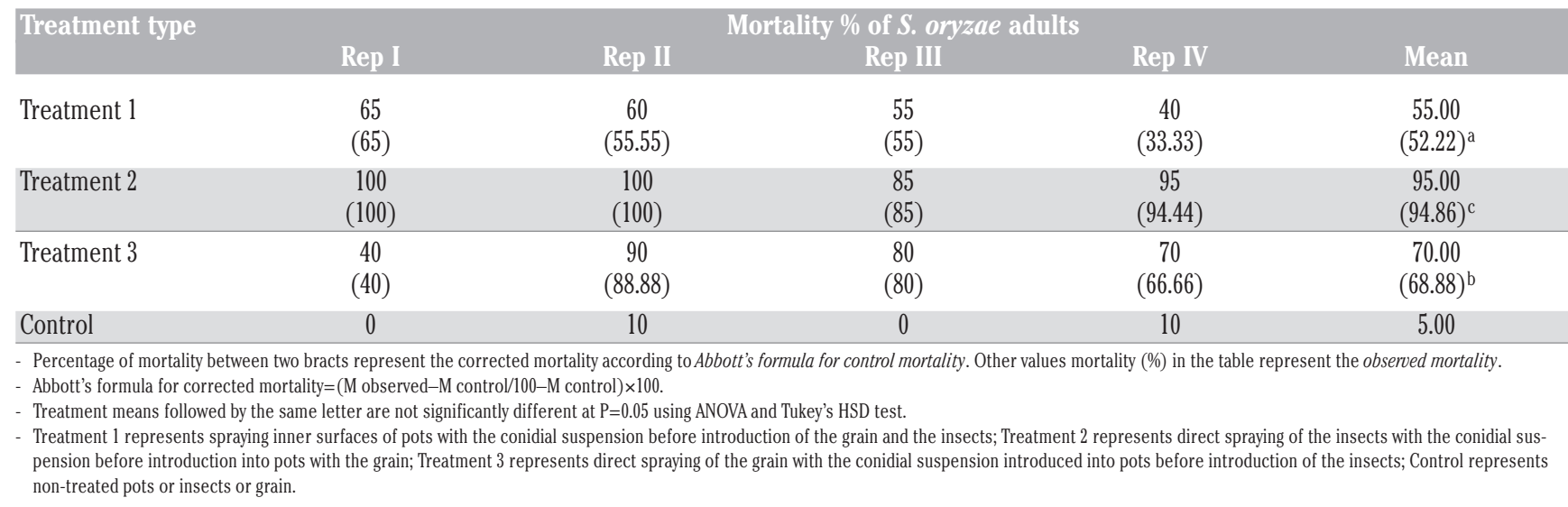




\section{Discussion}

It is well known that Fusarium avenaceum is a soil borne fungus. It may act as a saprophyte in the soil or plant pathogen of roots and stems of plants. As a plant pathogen, it can cause serious diseases to the plants it attacks, such as seed borne diseases of legumes (Kelloc et al., 1978), stem and root rot diseases in various pasture legumes (McGee \& Kellock, 1974; Lamprecht et al., 1988; Satyaprasad et al., 2000), head blight of wheat (Kang et al., 2005). However, the entomopathogenic effect of this fungus has been recently reported by a few investigators on certain insect species, such as the greenhouse whitefly, Trialeurodes vaporariorum, spruce budworm, Choristoneura fumiferana, and wheat stem sawfly, Cephus cinctus, (Strunz \& Strongman, 1988; Eleonora-Rojas et al., 2003; Sun, 2008). Our strain of $F$. avenaceum has demonstrated a high level of entomopathogenic effect against $S$. oryzae adults, and the direct spraying of the adult weevils with the fungus conidial suspension gave the highest mortality percentage compared to the other types of treatment or the Control. It is worthy of note that the emtomopathogenic activity of the fungus against $S$. oryzae adults has been demonstrated and reported here for the first time. In addition, there have been no reports of the entomopathogenic effect of $F$. avenaceum against any other coleopteran insects of stored grain.

The inoculation method used during bioassays through the direct spraying of the adult insects with the conidial suspension has been shown to be the most effective due to the direct contact of applied conidia with the treated insect's cuticle, so that the direct germination of applied conidia and the subsequent penetration of the germ tube into the insect's cuticle took place within a short time. This mode of action may explain the occurrence of the highest mortality percentage in the treated $S$. oryzae adults. It is known that the most common entomopathogenic fungi, such as Beauveria bassiana and Metarhizium anisopliae, can cause the highest mortalities in their host insects when applied directly to their host insects as biocontrol agents (Hidalgo et al., 1998; Moino et al., 1998; Rice \& Cogburn, 1999; Odour et al., 2000; Toshio, 2000; Sheeba et al., 2001). However, there are some limitations to this method of large-scale fungus inoculation to control $S$. oryzae infesting stored grain in large containers. For example, the relative increase in humidity in the vicinity of storage containers causes an increase in mold development that is not favorable for storage of stocked cereals. To reduce this effect, a certain number of fungus applications (e.g., 2 or 3 applications during the storage period) should be applied. The frequent application of entomopathogenic fungi as biocontrol agents of storage insects is not favorable for the stocked cereals due to the relative increase in the atmospheric humidity after application. However, the low number of applications for these biocontrol agents could be compensated by the horizontal transmission of these agents already introduced into storage containers during the earlier applications (Furlong \& Pell, 2001; Quesada-Moraga et al., 2004). The dead insects infected with the fungus with sporulation on the outer surfaces constitute the inoculum that can be horizontally transmitted to new insect infestation occurring during the storage period. This low number of fungus applications could be integrated into programs of $S$. oryzae management.

Morphological characteristics of the fungus strain described in the present research, especially those relevant to macroconidia and mycelium growth obtained in the fungus culture on SDA medium, conform to those described by other researchers. For example, Leslie and Summerell (2006) used Carnation Leaf Pieces Agar to cultivate the fungus but obtained similar effects. However, the culture of our fungus strain on SDA medium did not produce either microconidia or chlamydopspores so that the conidial suspension prepared from this culture and used for conducting bioassays has only contained the typical macroconidia of the fungus. The lack of microconidia and chlamydospores was explained by Nelson et al. (1994), Leslie and Summerell (2006), and Latiffa et al. (2010) who stated that the isolates of $F$. avenaceum did not usually produce chlamydospores, whereas some of these isolates may produce microconidia. Furthermore, they stated that if the microconidia are produced, they will be rare or only few in number, and have a fusoid shape with 1 or 2 septa.

The shape of macroconidia is the principal characteristic used to distinguish $F$. avenaceum species from other Fusarium species (Leslie \& Summerell, 2006). Accordingly, this characteristic is consistent and it can be applied if the cultures are carefully prepared and macroconidia are obtained from sporodochia; in this way, the shape of macroconidia can be used to identify the fungus species. Recently, a more accurate molecular identification of $F$. avenaceum isolates from other isolates of Fusarium species could be made, and more precisely, when primers and protocols for detecting $F$. avenaceum through real-time polymerase chain reaction assays are available (Waalwijk et al., 2004).

Until now, it has not been known how $F$. avenaceum, as entomopathogen, can kill its host insects. However, it is well known how this fungus, as plant pathogen, can attack and kill its host plant. Some explanation of the entomopathogenic effect of the fungus was based on production of toxins, such as beauvericin (Logrieco et al., 2002), fusarin C (Thrane, 1988; Abbas et al., 1989), and moniliformin (Rabie et al., 1982; Abbas et al., 1989; Chelkowski et al., 1990). Some strains of $F$. avenaceum can synthesize Enniatin cyclic peptides, primarily Enniatins A, B and B1 under laboratory conditions (Logrieco et al., 2002) but these Enniatins may have a role in plant pathogenicity (Haschek et al., 2001).

In conclusion, overall results indicate the effectiveness of $F$. avenceum against $S$. oryzae adults when applied directly to the adults by the spraying method of fungus conidia. However, further experiments are recommended using different doses of the fungus under a wide range of storage conditions of grain (e.g., different levels of temperature and relative humidity). Results obtained in the present research, in addition to those that could be obtained after conducting the recommended experiments, may be exploited in pest management strategies of $S$. oryzae on stored grain. This will be possible when virulent strains of the fungus with high entomopathogenic activity are available. Formulation of these effective strains can increase their efficacy, since it has already been shown that the formulation of other entomopathogenic fungi, such as Beauveria bassiana and Metarhizium anisopliae, increased their effectiveness and kept them viable for a longer period of time (Batta, 2004, 2008).

\section{References}

ABBAS H.K., MIROCHA C.J., GUNTHER R., 1989 - Mycotoxins produced by toxic Fusarium isolates obtained from agricultural and nonagricultural Arctic areas of Norway. - Mycopathologia 105: 143-152.

BATTA Y.A., 2004 - Control of rice weevil (Sitophilus oryzae L., Coleoptera: Curculionidae) with various formulations of Metarhizium anisopliae. - Crop Prot. 23: 103-108.

BATTA Y.A., 2008 - Control of main stored-grain insects with new formulations of entomopathogenic fungi in diatomaceous earth dusts. Internat. - J. Food Engin. 4: 1-16. Available from: http//www.bepress. com/ijfe/vol4/iss1/art9

B00TH C., 1971 - The Genus Fusarium. - Commonwealth Mycological Institute, Kew, Surrey, England: 237 pp.

CHELKOWSKI J., ZAWADZKI M., ZAJKOWSKI P., LOGRIECO A., BOTTALICO A., 1990 - Moniliformin production by Fusarium species. Mycotoxin Res. 6: 41-45.

DAL BELLO G., PADIN S., LOPEZ-LASTRA C., FABRIZIO M., 2000 - 
Laboratory evaluation of chemical-biological control of the rice weevil (Sitophilus oryzae L.) in stored grains. - J. Stored Products Res. 37: 77-84.

ELEONORA-ROJAS M., PEREA E.I., PINEDA Y.A., 2003 - Fusarium species on Trialeurodes vaporariorum from tobacco and kidney bean of Garcia Rovera, Santander, Colombia. - Revista Colomb. Entomol. 29: 1-10.

FANG L., SUBRAMANYAM B., ARTHUR F.H., 2002 - Effectiveness of Spinosad on four classes of wheat against five stored-products insects. - J. Econ. Ent. 95: 640-650.

FURLONG M.J., PELL J.K., 2001 - Horizontal transmission of entomopathogenic fungi by the Diamondback Moth. - Biol. Cont. 22: 288-299.

GOVINDAN K., NELSON S.J., 2009 - Insecticidal activity of twenty plant powders on mortality, adult emergence of Sitophilus oryzae L. and grain weight loss in paddy. - J. Biopesti. 2: 169-172.

GUPTA S., KRASNOFF S.B., UNDERWOOD N.L., RENWICK J.A.A., ROBERTS D.W., 1991 - Isolation of beauvericin as an insect toxin from Fusarium semitectum and Fusarium moniliforme var. subglutinans. - Mycopathologia 115: 185-189.

HASCHEK W.M., GUMPRECHT L.A., SMITH G., TUMBLESON M.E., CONSTABLE P.D., 2001 - Fumonisin toxicosis in swine: An overview of porcine pulmonary edema and current perspectives. Environ. Health Perspec. 109 (Suppl 2): 251-257.

HIDALGO E., MOORE D., LE PATOUREL G., 1998 - The effect of different formulations of Beauveria bassiana on Sitophilus zeamais in stored maize. - J. Stored Products Res. 34: 171-179.

KANG Z., ZINGEN-SELL I., BUCHENAUER H., 2005 - Infection of wheat spikes by Fusarium avenaceum and alterations of cell wall components in the infected tissue. - Europ. J. Plant Pathol. 111: 19-28.

KELLOCK A.W., STUBBS L.L., PARBERY D.G., 1978 - Seed-borne Fusarium avenaceum on subterranean clover and other pasture legumes. - Austr. J. Agric. Res. 29: 975-982.

LAMPRECHT S.C., KNOX-DAVIES P.S., MARASAS W.F.0., 1988 - Fung associated with root rot of annual Medicago spp. in South Africa. Phytophylactica 20: 281-286.

LATIFFAH Z., NURUL-IZZATI H., BAHARUDDIN S., 2010 - Fusarium species isolated from peat soil of Pondok Tanjung and Sungai Beriah, Perak. - Malaysian J. Microbiol. 6: 102-105.

LEE B., CHOI W., LEE S., PARK B., 2001 - Fumigant toxicity of essential oils and their constituent compounds towards the rice weevil, Sitophilus oryzae (L.). - Crop Prot. 20: 317-320.

LESLIE J.F., SUMMERELL B.A., 2006 - The Fusarium Laboratory Manual, $1^{\text {st }}$ ed. - Blackwell Publishing, Ames, Iowa, USA.

LOGRIECO A., RIZZO A., FERRACANE R., RITIENI A., 2002 - Occurrence of beauvericin and enniatins in wheat affected by Fusarium avenaceum head blight. - Appl. Environ. Microbiol. 68: 82-85.

MCGEE D.C., KELLOCK A.W., 1974 - Fusarium avenaceum, a seedborne pathogen of subterranean clover roots. - Aust. J. Agric. Res. 25: 549557.

MOINO JR A., ALVES S.B., PEREIRA R.M., 1998 - Efficacy of Beauveria bassiana (Bal.) Vuilemin isolates for control of stored-grain pests. - J. Appl. Entomol. 122: 201-205.

NELSON P.E, DIGNANI M.C., ANAISSIE E.J., 1994- Taxonomy, biology, and clinical aspects of Fusarium species. - Clin. Microbiol. Rev. 7: 479-504.
ODOUR G.I., SMITH S.M., CHANDI E.A., KARANJA L.W., AGANO J.O., MOORE D., 2000 - Occurrence of Beauveria bassiana on insect pests of stored maize in Kenya. - J. Stored Products Res. 36: 177 185 .

PADIN S., DAL BELLO G., FABRIZIO M., 2002 - Grain loss caused by Tribolium castaneum, Sitophilus oryzae and Acanthoscelides obtectus in stored durum wheat and beans treated with Beauveria bassiana. - J. Stored Products Res. 38: 69-74.

PUNGITORE C.R., GARCÍA M., GIANELLO J.C., SOSA M.E., TONN C.E., 2005 - Insecticidal and antifeedant effects of Junellia aspera (Verbenaceae) triterpenes and derivatives on Sitophilus oryzae (Coleoptera: Curculionidae). - J. Stored Products Res. 41: 433-443.

OUESADA-MORAGA E., SAMTOS-OUIROS R., VALVERDE-GRACIA P., SANTIAGO-ALVAREZ C., 2004 - Virulence, horizontal transmission, and sub-lethal reproductive effects of Metarhizium anisopliae (Anamorphic fungi) on the German cockroach (Blattodea: Blattellidae). - J. Invertebr. Pathol. 87: 51-58.

RABIE C.J., MARASAS W.F.0., THIEL P.G., LÜBBEN A., VLEGGAAR R., 1982- Moniliformin production and toxicity of different Fusarium species from southern Africa. - Appl. Environ. Microbiol. 43: 517521.

RICE W.C., COGBURN R.R., 1999 - Activity of the entomopathogenic fungus Beauveria bassiana (Deuteromycotina: Hyphomycetes) against three coleopteran pests of stored grains. - J. Econ. Entomol. 92: 691-694.

SATYAPRASAD K., BATEMAN G.L., WARD E., 2000 - Comparisons of isolates of Fusarium avenaceum from white lupine and other crops by pathogenicity tests, DNA analyses, and vegetative compatibility tests. - J. Phytopathol. 148: 211-219.

SHEEBA G., SESHARDI S., RAJA N., JANARTHANA S., IGNACINUTHA S., 2001 - Efficacy of Beauveria bassiana for control of the rice weevil Sitophilus oryzae L. (Coleoptera: Curculionidae). - Appl. Entomol. Zool. 36: 117-120.

STRUNZ G.M., STRONGMAN D.B., 1988 - Insecticidal Metabolites from Fusarium avenaceum, a Fungus Associated with Foliage of Abies balsamea Infested by Spruce Budworm, Choristoneura fumiferana. In: Biotechnology for crop protection, Chapter 8, ACS Symposium Series, Vol. 379. - Washington, DC: 110-116.

SUN Z., 2008 - The pathogenicity of Fusarium Spp. to wheat stem sawfly, Cephus cinctus Norton (Hymenoptera: Cephidae), Ph. D Thesis in Plant Sciences. - Montana State University, Bozeman, Montana, USA: $156 \mathrm{pp}$.

TEETOR-BARSCH G.H., ROBERTS D.W., 1983 - Entomogenous Fusarium species. - Entomopathologica 84: 3-16.

THRANE U., 1988 - Screening for fusarin C production by European isolates of Fusarium species. - Mycotoxin Res. 4: 2-10.

TOSHIO M., 2000 - Microbial control of the Diamondback moth, Plutella xylostella, by an entomopathogenic fungus, Beauveria bassiana. II. Effect of temperature on mycoses and conidial invasion time. Japan. J. Appl. Entomol. Zool. 44: 177-182.

WAALWIJK C., VAN DER HEIDE R., DE VRIES I., VAN DER LEE T., SCHOEN C., COSTREL DE CORAINVILLE G., et al., 2004 . Quantitative detection of Fusarium species in wheat using TaqMan. - Europ. J. Plant Pathol. 110: 481-494.

YANKANCHI S.R., GADACHE A.H., 2010 - Grain protectant efficacy of certain plant extracts against rice weevil, Sitophilus oryzae L. (Coleoptera: Curculionidae). - J. Biopesticides 3: 511-513. 